\title{
The predictability of serum anti-Müllerian level in IVF/ICSI outcomes for patients of advanced reproductive age
}

\author{
Robert KK Lee ${ }^{1,2+}$, Frank SY Wu ${ }^{1 \dagger}$, Ming-Huei Lin', Shyr-Yeu Lin ${ }^{1}$ and Yuh-Ming Hwu ${ }^{1,3^{*}}$
}

\begin{abstract}
Background: The role of serum anti-Müllerian hormone $(\mathrm{AMH})$ as predictor of in-vitro fertilization outcomes has been much debated. The aim of the present study is to investigate the practicability of combining serum AMH level with biological age as a simple screening method for counseling IVF candidates of advanced reproductive age with potential poor outcomes prior to treatment initiation.

Methods: A total of 1,538 reference patients and 116 infertile patients aged greater than or equal to 40 years enrolled in IVF/ICSI cycles were recruited in this retrospective analysis. A reference chart of the age-related distribution of serum AMH level for Asian population was first created. IVF/ICSI patients aged greater than or equal to 40 years were then divided into three groups according to the low, middle and high tertiles the serum AMH tertiles derived from the reference population of matching age. The cycle outcomes were analyzed and compared among each individual group.

Results: For reference subjects aged greater than or equal to 40 years, the serum $\mathrm{AMH}$ of the low, middle and high tertiles were equal or lesser than $0.48,0.49-1.22$ and equal or greater than $1.23 \mathrm{ng} / \mathrm{mL}$ respectively. IVF/ICSI patients aged greater than or equal to 40 years with $\mathrm{AMH}$ levels in the low tertile had the highest cycle cancellation rate (47.6\%) with zero clinical pregnancy. The nadir AMH level that has achieved live birth was $0.56 \mathrm{ng} / \mathrm{mL}$, which was equivalent to the 36.4th percentile of AMH level from the age-matched reference group. The optimum cut-off levels of $\mathrm{AMH}$ for the prediction of nonpregnancy and cycle cancellation were 1.05 and $0.68 \mathrm{ng} / \mathrm{mL}$, respectively.
\end{abstract}

Conclusions: Two criteria: (1) age greater than or equal to 40 years and (2) serum AMH level in the lowest tertile (equal or lesser than 33.3rd percentile) of the matching age group, may be used as markers of futility for counseling IVF/ICSI candidates.

\section{Background}

One of the most difficult aspects of assisted reproductive treatment (ART) is to identify and counsel patients with very low or virtually no chance of achieving live birth. A report by the Ethics Committee of the American Society of Reproductive Medicine (ASRM) nevertheless has provided a valuable guideline when considering fertility treatment for patients with extremely poor prognosis. According to the report, patients are defined as having "poor prognosis" when the likelihood of a given ART

\footnotetext{
* Correspondence: hwu4416@yahoo.com.tw

+ Contributed equally

'Department of Obstetrics and Gynecology, Mackay Memorial Hospital,

Taipei, Taiwan

Full list of author information is available at the end of the article
}

treatment achieving live birth is very low but not nonexistent ( $>1 \%$ and $\leq 5 \%$ per cycle); while those with essentially no chance of achieving live birth with ART treatment ( $\leq 1 \%$ per cycle) are considered as "futility" [1].

Prior to the advancements of ultrasound and immunoassay, the initial assessment of fecundity was largely based on one's chronological age. Although the agerelated decline in reproductive capacity has been well documented in general population [2], the rate of fertility decline can vary considerably among individual women of the same age $[3,4]$, indicating that "ovarian aging" may not be unequivocally dictated by chronological aging. With the paradigms of modern ART emphatically stressing the importance of treatment

\section{() Biomed Central}


individualization and optimization, other markers are clearly in need.

Lacking a precise definition, the ovarian age is best represented by ovarian reserve, the functional potential of ovaries at any given time. Before initiating ART treatment, ovarian reserve can be assessed ultrasonically by antral follicle count (AFC), the ovarian volume and ovarian blood flow, by endocrine markers such as basal follicular stimulating hormone (FSH), inhibin-B, estradiol and anti-Müllerian hormone (AMH), and/or by ovarian stimulatory tests such as the clomiphene citrate challenge test (CCCT), the exogenous FSH ovarian reserve test (EFORT) and the gonadotropin agonist stimulation test (GAST) [3]. The ultimate goal of these tests is to provide a more accurate prediction of the potential success for patients prior to treatment initiation, thus enabling a more feasible, patient oriented treatment approach.

The aim of this study is therefore to assess the practicability of using serum AMH level, in conjunction with chronological age, for screening and counseling advanced-aged IVF candidates with high probability of poor outcomes prior to treatment initiation. For the present study, advanced age is defined as equal or above forty years old, and poor outcomes are defined as IVF/ ICSI cycles resulting either in cancellation or nonpregnancy.

\section{Methods}

\section{Study subjects}

Medical records were retrospectively examined for patients who sought fertility consultation or treatment at the Infertility Division of the Department of Obstetrics-Gynecology, Mackay Memorial Hospital from December 1st, 2006 to May 31st, 2010. The study protocol was approved by the Institutional Review Board of Mackay Memorial Hospital in Taipei, Taiwan.

For the reference population, the inclusion criteria were patients who fitted the medical definition of infertility "one year of unprotected intercourse but not pregnant" and without any of the following exclusion criteria: (1) menopause or premature ovarian failure status (Day 3 serum FSH level > $10 \mathrm{IU} / \mathrm{mL}$ ), (2) history of ovarian or adnexal surgery, (3) suspicious findings of ovarian malignancy, and (4) presence of endocrine disorders such as diabetes mellitus, hyperprolactinemia, thyroid dysfunction, congenital adrenal hyperplasia, Cushing's syndrome, adrenal insufficiency, and polycystic ovary syndrome. In addition, severe underweight or overweight patients were also excluded (BMI $<20$ or $>$ 27 ). For the analysis of IVF patients $\geq 40$ years of age, the inclusion criteria were the same as the ones for reference population, with the addition of having undergone IVF during the same period of time.

\section{Study design}

The variation of AMH levels among different races and ethnicities has been well documented in the study by Seifer et al. [5]. Since the chart for age-related distribution of AMH levels has not been established for Asian population, it was pertinent that an age-specific reference values must first be formulated. After applying the above exclusion criteria, AMH data of 1,538 infertility patients between the ages of 23 to 46 were obtained. For each age group, the AMH levels were further stratified into respective percentiles, serving as reference values for the next phase of this study.

The relationship between age and serum AMH levels on IVF/ICSI outcomes in infertility patients $\geq 40$ years of age was investigated in the following phase. Of all the reference infertility patients $\geq 40$ years of age $(n=378)$, only the ones who had undergone IVF/ICSI were enrolled $(\mathrm{n}=116)$. These 116 subjects were further divided into three groups according to the low, middle and high tertiles $\left(\leq 33.3^{\text {rd }}\right.$ percentile, $33.4-66.6^{\text {th }}$ percentile, and $\geq 66.7^{\text {th }}$ percentile) from the AMH reference values for the 378 patients $\geq 40$ years of age. The cycle outcomes were then analyzed and compared among each individual group.

The nadir serum AMH levels capable of achieving live birth were identified and ranked according to the reference $\mathrm{AMH}$ values of corresponding reference age groups. Correlations between AMH levels and outcomes were also observed for the infertility patients aged 35 or younger who underwent IVF/ICSI during the same period $(\mathrm{n}=323)$. Lastly, the serum AMH cut-off values for the prediction of nonpregnancy and cycle cancellation for IVF/ICSI patients with aged 40 and above were further quantified using the receiver operating characteristic (ROC) curve analysis.

\section{Ovarian stimulation protocols}

All IVF/ICSI patients received either the GnRH agonist long protocol or the GnRH antagonist protocol. All patients received a starting dosage of 375 IU of recombinant follicle-stimulating hormone (r-FSH; Gonal-F; Serono Laboratories, Aubonne, Switzerland) and 150 IU of human menopausal gonadotropin (hMG; Menopur; Ferring GmbH, Kiel, Germany) for three consecutive days, and the dosage was then adjusted every two to three days in accordance with the follicle growth until the day of hCG administration. For the GnRH agonist group, leuprolide acetate (Takeda Pharma GmbH, Stolberg, Germany) was given at a daily dose of $1 \mathrm{mg}$, starting on the twenty-first day of the previous menstrual cycle until the serum levels of estradiol fell below $30 \mathrm{pg} /$ $\mathrm{mL}$, and patients then began daily gonadotropin injection. In the GnRH antagonist group, patients began daily administration of r-FSH and hMG on the second 
or third day of the menstrual cycle. After at least one follicle reached $14 \mathrm{~mm}$ in diameter, daily injection of $0.25 \mathrm{mg}$ of cetrorelix (Cetrotide; Serono, Baxter Oncology $\mathrm{GmbH}$, Halle, Germany) was given until the day of hCG administration.

When at least two follicles reached $18 \mathrm{~mm}$ in diameter, 10,000 IU hCG (Pregnyl; Schering-Plough, Kenilworth, NJ, USA) was administered and oocyte retrieval was performed 34-36 hours later. Conventional IVF or ICSI was conducted 4-6 hours post oocyte retrieval. For IVF, each oocyte was inseminated with $20 \times 10^{3}$ motile spermatozoa in a single droplet containing $20 \mu \mathrm{l}$ of fertilization medium (Quinn's Advantage Fertilization medium; SAGE IVF Inc. Trumbull, Connecticut, U.S.A.). For ICSI, 1-2 $\mu$ l washed spermatozoa were placed in $7 \%$ polyvinylpyrrolidone (PVP; SAGE IVF Inc.) and a sperm was injected into each denuded oocyte using standardized techniques. Each embryo was cultured in a single droplet containing $20 \mu \mathrm{l}$ of medium (Quinn's Advantage Cleavage medium; SAGE IVF Inc.) and incubated under the atmospheric composition of $5 \% \mathrm{CO}_{2}, 5 \% \mathrm{O}_{2}$ and $90 \% \mathrm{~N}_{2}$ at $37^{\circ} \mathrm{C}$. All embryo transfers were performed at 72 hours post oocyte retrieval.

\section{Luteal support and confirmation of pregnancy}

The luteal phase was supported by intramuscular injection of $50 \mathrm{mg}$ of progesterone and vaginal supplementation of $300 \mathrm{mg}$ micronized progesterone (Progeffik; Effik, Paris, France) or Crinone 8\% progesterone gel (Columbia Laboratories, Inc., Livingston, NJ) once per day. Serum hCG was measured 14 days after oocyte retrieval and a value above $5 \mathrm{IU} / \mathrm{ml}$ was designated as positive pregnancy. Clinical pregnancy was defined as a pregnancy diagnosed by ultrasonographic visualization of the gestational sac. Viable pregnancy was defined as gestation age greater than $7^{\text {th }}$ weeks with documented fetal cardiac activity by ultrasound.

\section{Serum AMH measurement}

AMH levels were measured by enzyme-linked immunosorbent assay kit (ELISA, Diagnostic Systems Laboratories, Webster, TX). The detection range of the assay was between $0.025-15 \mathrm{ng} / \mathrm{mL}$ with the detection limit $(0.017 \mathrm{ng} / \mathrm{mL})$. Values below the detection limits were considered as zero. The intra-and-interassay variation coefficients were $4.6 \%$ and $8.0 \%$ respectively. Samples from all subjects were obtained via venipuncture and analyzed by the same laboratory (Department of Immunoassay, Mackay Memorial Hospital, Taipei, Taiwan). The samples were processed according to the manufacturer instructions by centrifuging at $1400 \times \mathrm{g}$ for 10 minutes to separate cellular contents and the debris, then the serum was transferred to sterile polypropylene tubes to be preserved at $-70^{\circ} \mathrm{C}$ until assayed.

\section{Statistical analysis}

Statistical analysis was performed using SigmaPlot (Systat Software Inc., Chicago, IL, USA) and MedCalc 10.2 (MedCalc Software, Mariakerke, Belgium). Continuous variables were presented as mean and standard deviation (SD). For categorical variables, the values were presented as raw frequencies with corresponding percentages, and the between-group differences were assessed either by Chi square test with Yates correction if needed, or by Fisher exact test. The 95\% confidence interval of the binomial distribution for clinical pregnancies in each of the three groups were calculated by the modified Wald method. Receiver operating characteristic (ROC) curves were generated to investigate the predictability of AMH levels in IVF cycle cancellation and nonpregnancy. The sensitivity, specificity, positive and negative predictive values were calculated for the optimal AMH cut-off levels determined by ROC curve analysis. The results were considered statistically significant at $\mathrm{p}<0.05$.

\section{Results}

Both the mean and median AMH values of the reference group showed a progressive decline with advancing age (Table 1). The low, middle, and high tertiles of serum AMH for reference subjects with aged 40 years and above were $\leq 0.48,0.49-1.22$ and $\geq 1.23 \mathrm{ng} / \mathrm{mL}$ respectively. The mean age differences among the three groups analyzed by ANOVA were found to be statistically insignificant. The sample size was considered sufficient by one tailed post hoc power analysis $(\alpha=0.05$ and a power of $80 \%$ ).

The IVF/ICSI outcomes for subjects of age $\geq 40$ years are presented in Table 2. After dividing them according to the low, middle and high tertiles from the AMH reference values for patients with age $\geq 40$ years, a trend of negative cycle outcomes was observed toward the lower end of AMH tertile. Subjects with AMH concentrations in the low tertile had zero clinical pregnancy, which differed significantly from those of the middle $(23.7 \%, \mathrm{p}<0.02)$ and the high tertiles $(29.8 \%, \mathrm{p}<0.0001)$. On the other hand, women with $\mathrm{AMH}$ concentrations in the low tertile had the highest rate of cycle cancellation (47.6\%), which also differed significantly from those of the middle $(15.7 \%, \mathrm{p}<0.04)$ and the high tertiles $(1.7 \%, \mathrm{p}$ $<0.01)$. When comparing the outcomes between the higher two tertiles, a significant difference was noted only for cycle cancellation $(15.7 \%$ vs. $1.7 \%, \mathrm{p}=0.02)$ but not for clinical pregnancy rate $(23.7 \%$ vs. $29.8 \%$, p $>0.05$ ). The $95 \%$ confidence interval of the binomial distribution for clinical pregnancies from the low to high tertile was zero to 16 percent, 13-39 percent and 19-42 percent respectively. 
Table 1 The age-related distribution chart of serum AMH level $(\mathrm{ng} / \mathrm{mL})$ for reference infertility patients

\begin{tabular}{|c|c|c|c|c|c|c|c|c|c|}
\hline Age & Mean \pm SD & $5^{\text {th }}$ centile & $10^{\text {th }}$ centile & $25^{\text {th }}$ centile & Median & $75^{\text {th }}$ centile & $90^{\text {th }}$ centile & $95^{\text {th }}$ centile & $n$ \\
\hline$\leq$ & $4.07 \pm 1.98$ & 1.74 & 1.88 & 2.61 & 3.38 & 5.46 & 7.12 & 8.57 & 36 \\
\hline 27 & $3.82 \pm 1.93$ & 0.30 & 1.39 & 2.45 & 3.43 & 5.17 & 6.42 & 7.60 & 30 \\
\hline 28 & $4.41 \pm 2.01$ & 0.77 & 1.80 & 2.78 & 4.47 & 5.75 & 7.33 & 7.70 & 45 \\
\hline 29 & $3.79 \pm 1.09$ & 1.08 & 1.41 & 2.27 & 3.48 & 5.31 & 6.74 & 7.16 & 70 \\
\hline 30 & $3.77 \pm 1.96$ & 1.03 & 1.15 & 2.26 & 3.38 & 5.52 & 6.57 & 6.90 & 82 \\
\hline 31 & $3.61 \pm 2.14$ & 0.83 & 1.23 & 1.81 & 3.20 & 4.84 & 6.85 & 7.68 & 104 \\
\hline 32 & $3.80 \pm 2.08$ & 0.68 & 1.11 & 2.23 & 3.62 & 5.21 & 6.97 & 7.68 & 127 \\
\hline 33 & $3.29 \pm 1.90$ & 0.88 & 1.09 & 1.66 & 2.91 & 4.63 & 5.97 & 6.80 & 129 \\
\hline 34 & $2.81 \pm 1.99$ & 0.53 & 0.75 & 1.24 & 2.35 & 3.78 & 6.01 & 7.18 & 149 \\
\hline 35 & $3.15 \pm 1.89$ & 0.67 & 0.83 & 1.70 & 2.83 & 4.51 & 5.79 & 6.57 & 104 \\
\hline 36 & $3.08 \pm 1.83$ & 0.81 & 1.06 & 1.33 & 2.77 & 4.38 & 5.40 & 6.57 & 86 \\
\hline 37 & $2.61 \pm 1.65$ & 0.75 & 0.78 & 1.12 & 2.47 & 3.49 & 5.12 & 5.67 & 69 \\
\hline 38 & $2.03 \pm 1.40$ & 0.06 & 0.19 & 0.88 & 1.91 & 2.94 & 3.87 & 4.64 & 73 \\
\hline 39 & $1.45 \pm 1.35$ & 0.05 & 0.11 & 0.48 & 1.07 & 2.02 & 3.14 & 4.65 & 56 \\
\hline 40 & $1.68 \pm 1.36$ & 0.11 & 0.13 & 0.63 & 1.42 & 2.41 & 3.65 & 4.20 & 126 \\
\hline 41 & $1.18 \pm 1.32$ & 0.02 & 0.05 & 0.29 & 0.86 & 1.35 & 3.04 & 3.48 & 88 \\
\hline 42 & $0.91 \pm 0.97$ & 0.01 & 0.05 & 0.23 & 0.60 & 1.24 & 2.34 & 3.53 & 47 \\
\hline 43 & $0.79 \pm 0.77$ & 0.00 & 0.05 & 0.06 & 0.63 & 1.50 & 2.09 & 2.48 & 43 \\
\hline 44 & $0.69 \pm 0.61$ & 0.06 & 0.08 & 0.28 & 0.52 & 0.98 & 1.36 & 2.36 & 32 \\
\hline 45 & $0.66 \pm 0.66$ & 0.13 & 0.14 & 0.32 & 0.54 & 0.67 & 1.12 & 2.73 & 26 \\
\hline 46 & $0.50 \pm 0.40$ & 0.00 & 0.00 & 0.10 & 0.52 & 0.81 & 1.11 & 1.14 & 16 \\
\hline All & $2.71 \pm 2.04$ & 0.14 & 0.40 & 0.65 & 2.36 & 3.09 & 5.78 & 6.82 & 1538 \\
\hline$\geq 40$ & $1.17 \pm 1.99$ & 0.05 & 0.06 & 0.32 & 0.78 & 1.56 & 2.91 & 3.53 & 378 \\
\hline
\end{tabular}

The lowest serum AMH level that achieved live birth in the group aged $\geq 40$ years was $0.56 \mathrm{ng} / \mathrm{mL}$, which was equivalent to the $36.4^{\text {th }}$ percentile of $\mathrm{AMH}$ level from the reference group of the same age. For the group aged $\leq 35$ years, live birth was achievable even for subjects with diminished ovarian reserve. The nadir AMH level that achieved live birth in that group was $0.26 \mathrm{ng} / \mathrm{mL}$, which was equivalent to the $1.7^{\text {th }}$ percentile of $\mathrm{AMH}$ level from the reference group of the same age.

With respect to the prediction of cycle cancellation and nonpregnancy for infertility patients aged $\geq 40$ years, AMH demonstrated a high discriminative ability with respective areas under curve (AUC) of 0.77 and 0.66 by ROC curve analysis. The optimal cut-off level of $\mathrm{AMH}$ for the prediction of IVF cycle cancellation was

Table 2 Outcomes of IVF/ICSI cycles in women of advanced reproductive age ( $\geq 40$ years old)

\begin{tabular}{|c|c|c|c|c|}
\hline & \multirow[b]{2}{*}{ Total subjects } & \multicolumn{3}{|c|}{ Serum AMH tertiles $(\mathrm{ng} / \mathrm{mL})$} \\
\hline & & $\underset{(\leq 0.48)}{\text { Low }}$ & $\begin{array}{c}\text { Middle } \\
(0.49 \sim 1.22)\end{array}$ & $\begin{array}{c}\text { High } \\
(\geq 1.23)\end{array}$ \\
\hline Total cycle & 116 & 21 & 38 & 57 \\
\hline Cancelled cycle (\%) & $17(14.7)$ & $10(47.6)^{\S}$ & $6(15.7)^{*}$ & $1(1.7)$ \\
\hline Mean age & $41.5 \pm 1.4$ & $42.8 \pm 2.3$ & $41.1 \pm 1.3$ & $41.3 \pm 1.4$ \\
\hline Peak E2 level (pg/mL) & $1542.1 \pm 1146.5$ & $802.6 \pm 748.9$ & $1050 \pm 699$ & $2095.8 \pm 1156.2$ \\
\hline Number of oocytes retrieved & $6.1 \pm 4.6$ & $2.4 \pm 2.9$ & $4.7 \pm 2.5$ & $8.1 \pm 5.1$ \\
\hline Number of mature oocytes & $4.7 \pm 3.7$ & $1.5 \pm 1.73$ & $3.9 \pm 2.5$ & $6.3 \pm 3.9$ \\
\hline Embryos obtained & $3.8 \pm 2.9$ & $1.8 \pm 2.4$ & $3.1 \pm 2.2$ & $4.8 \pm 3.1$ \\
\hline Embryos transferred & $2.8 \pm 1.2$ & $1.6 \pm 1.3$ & $2.6 \pm 1.0$ & $3.2 \pm 1.0$ \\
\hline Clinical pregnancy per cycle (\%) & $26(22.4)$ & $0(0)^{\S}$ & $9(23.7)$ & $17(29.8)$ \\
\hline Abortion per cycle (\%) & $7(26.9)$ & $0(0)$ & $0(0)$ & $7(41.2)$ \\
\hline Viable pregnancy per cycle (\%) [FHB (+) \& $>7$ wks.] & 19 (16.4) & $0(0) \bigotimes$ & $9(23.7)$ & $10(17.5)$ \\
\hline
\end{tabular}

$\S p<0.05$ compared with the middle tertile and the high tertile

${ }^{*} p<0.05$ compared with the high tertile

$\otimes p<0.05$ compared with the middle tertile 
$0.68 \mathrm{ng} / \mathrm{mL}(\mathrm{p}<0.05)$, with specificity of $85.1 \%$ and negative predictive value of $92.0 \%$. The optimal cut-off level of AMH for the prediction of IVF nonpregnancy was $1.05 \mathrm{ng} / \mathrm{mL}(\mathrm{p}<0.05)$, with specificity of $86.7 \%$ and positive predictive value of $91.4 \%$. The cut-off levels of AMH for IVF cycle cancellation $(0.68 \mathrm{ng} / \mathrm{mL})$ and nonpregnancy $(1.05 \mathrm{ng} / \mathrm{mL})$ corresponded to the $43.8^{\text {th }}$ and $56.8^{\text {th }}$ percentile of the reference serum AMH level from the matching age group respectively. The complete sensitivity, specificity, positive and negative predictive values are summarized in Table 3.

\section{Discussion}

The most pertinent concern to the infertile couple has always been the success rate of specific ART treatments. Therefore, numerous studies have been dedicated to identify reliable markers that may help in predicting outcomes in IVF cycles, as well as the feasibility of applying these markers in patient counseling prior to treatment initiation. A recent meta-analysis has concluded that female age, duration of subfertility, basal FSH level and number of retrieved oocytes are all predictors of pregnancy in IVF cycles [6]. However, many other potential markers, including serum AMH level, were not incorporated as the factors analyzed in that study.

Since its discovery, AMH has been a promising marker in various clinical setting of ART. Initially viewed as an accurate marker of ovarian reserve $[7,8], \mathrm{AMH}$ was subsequently found to be a reliable predictor of controlled ovarian hyperstimulation for both poor $[9,10]$ and hyper responses [11,12]. In addition, one study reported $\mathrm{AMH}$ to be a competent surrogate marker for antral follicle count in the diagnosis of PCOS by the Rotterdam Criteria [13]. Nevertheless, the relationship between serum AMH level and IVF pregnancy outcome still has not been fully elucidated. A recent review by Broekmans et al. has concluded that ovarian reserve tests, including AMH, were not good predictors of pregnancy in IVF cycles [14].

There are several possible rationales for the poor performance of $\mathrm{AMH}$ in predicting pregnancy in IVF cycles. First of all, the international assay standard for $\mathrm{AMH}$ measurement is lacking. Up to dates, only few studies have attempted to create age-specific serum $\mathrm{AMH}$ values for the infertile population [15] and healthy cohorts $[16,17]$. Secondly, while these studies have all observed a similar trend of steady decrement of $\mathrm{AMH}$ level with advanced age, a wide range of distribution of AMH levels among each age group was also noted [15-17]. The wide variability was also observed in the AMH data from our reference group study, and that was one of the primary reasons that median was used for analysis instead of arithmetic mean. Furthermore, among most studies that investigated the predictability of AMH levels in IVF pregnancy, no specific age group was targeted for the enrolled subjects. Therefore, a wide range of cut-off values was presented $(0.10-2.70 \mathrm{ng} / \mathrm{mL})$ $[7,18-25]$ with various sensitivity, specificity, positive and negative predictive values. In short, serum AMH value alone may not be a sufficient predictor of pregnancy in IVF cycles without other considering factors.

Furthermore, the quality and quantity of oocytes are both important determinants for the success in ART. Several studies have demonstrated that serum AMH may also possess the additional ability to predict the quality of oocytes and embryos [18,26-28], while others have failed to replicate such relationship $[21,29,30]$. In a well-designed study by Wang et al., the authors revealed that both the clinical pregnancy rate per retrieval and live birth rate per embryo transfer did not differ significantly across all three AMH tertiles $(\leq 0.29,0.30-1.20$ and $\geq 1.21 \mathrm{ng} / \mathrm{ml}$ ) for women aged $<34$ years. This indicated that favorable outcomes may still be attained for the infertile patients of younger age on the basis of biologically competent oocytes, despite of the diminished ovarian reserve [31]. The observation drawn from the present study also demonstrated that pregnancy was still achievable even in patients younger than 35 years old with extremely low $A M H$ level $\left(0.26 \mathrm{ng} / \mathrm{mL} ; 1.7^{\text {th }}\right.$ percentile). These findings concurred with the conclusions drawn from the recent meta-analysis by van Loendersloot et al., which found that female age, hence oocyte quality, was the most important predictor of pregnancy in IVF cycles among almost all of the analyzed studies [6].

On the other hand, the present study disclosed that for women of advanced reproductive age $(\geq 40)$, having AMH concentrations in the higher two tertiles was associated with nonsignificant difference in clinical pregnancy rate, which differed significantly from those with $\mathrm{AMH}$ level in the lowest tertile. In addition, no live birth was achieved for women with AMH in the lowest tertile with extremely high cycle cancellation rate. These

Table 3 Prediction of cycle cancellation and nonpregnancy by serum AMH levels in women of advanced reproductive age ( $\geq \mathbf{4 0}$ years old)

\begin{tabular}{lccccccc}
\hline & Cut-off AMH level (ng/mL) & ROC $_{\text {AUC }}$ & Sensitivity (\%) & Specificity (\%) & PPV (\%) & NPV (\%) & Significance level \\
\hline Cycle cancellation & 0.68 & 0.77 & 64.7 & 85.1 & 47.8 & 92.0 & $p=0.0001$ \\
Nonpregnancy & 1.05 & 0.65 & 42.7 & 86.9 & 91.4 & 31.7 & $p=0.022$ \\
\hline
\end{tabular}


results demonstrated that for women $\geq 40$ years old with AMH level in the lowest tertile, poor IVF/ICSI cycle outcomes could be expected due to poor oocyte quantity as well as quality. Though the range of $\mathrm{AMH}$ tertiles were defined differently, similar observation was also made in the study by Wang et al for women of advanced reproductive age [31].

One of the limitations of the present study was the relative small sample size $(n=116)$ in the IVF group $\geq$ 40 years old. Being a retrospective study which targeted only on a specific group of infertile population, a larger sample size is indeed needed in the future to confirm the results of this study. Furthermore, the results from the present study were to simply present an easier and more reliable counseling tool for evaluating and identifying patients of potential poor outcome, rather than a tool of exclusion. The patients should always have final decision of whether or not to receive treatment.

\section{Conclusions}

To the best of our knowledge, this is the first ever study that investigated the lower limits of serum AMH level capable of achieving viable pregnancy in advanced-aged IVF/ICSI patients, specifically those equal and over forty years old. In addition, from our data, we were able to derive the serum AMH cut-off values that may reliably predict the likelihood of cycle cancellation as well as nonpregnancy for IVF/ICSI patients equal and over forty years old. To sum up, we propose two simple criteria for patient counseling: (1) age equal and over forty years and (2) serum AMH level in the low tertile $\left(\leq 33.3^{\text {rd }}\right.$ percentile) of the matching age group, as the markers of futility for IVF/ICSI due to high cancellation rate and slim chance for clinical pregnancy.

\section{Author details \\ 'Department of Obstetrics and Gynecology, Mackay Memorial Hospital, Taipei, Taiwan. ${ }^{2}$ Department of Obstetrics and Gynecology, Taipei Medical University, Taipei, Taiwan. ${ }^{3}$ Mackay Medicine, Nursing and Management College, Taipei, Taiwan.}

\section{Authors' contributions}

RKKL participated in the original design of the study and drafted the manuscript. FSYW carried out the data collection and performed the statistical analysis. YMH supervised the study and validated the data. MHL and SYL assisted in the study organization and the data collection. All of authors have read and approved the final manuscript.

\section{Competing interests}

The authors declare that they have no competing interests.

Received: 6 May 2011 Accepted: 15 August 2011

Published: 15 August 2011

\section{References}

1. The Ethics Committee of the American Society for Reproductive Medicine: Fertility treatment when the prognosis is very poor or futile. Fertil Steril 2009, 92:1194-1197.
2. Templeton A, Morris JK, Parslow W: Factors that affect outcome of in-vitro fertilisation treatment. Lancet 1996, 348:1402-1406.

3. Broekmans FJ, Kwee J, Hendriks DJ, Mol BW, Lambalk CB: A systematic review of tests predicting ovarian reserve and IVF outcome. Hum Reprod Update 2006, 12:685-718.

4. te Velde ER, Pearson PL: The variability of female reproductive ageing. Hum Reprod Update 2002, 8:141-154.

5. Seifer DB, Golub ET, Lambert-Messerlian G, Benning L, Anastos K, Watts DH, Cohen MH, Karim R, Young MA, Minkoff $H$, Greenblatt RM: Variations in serum mullerian inhibiting substance between white, black, and Hispanic women. Fertil Steril 2009, 92:1674-1678.

6. van Loendersloot LL, van Wely M, Limpens J, Bossuyt PM, Repping S, van der Veen F: Predictive factors in in vitro fertilization (IVF): a systematic review and meta-analysis. Hum Reprod Update 2010, 16:577-589.

7. Van Rooij IA, Broekmans FJ, te Velde ER, Fauser BC, Bancsi LF, Jong FH, Themmen AP: Serum anti-Müllerian hormone levels: a novel measure of ovarian reserve. Hum Reprod 2002, 17:3065-3071.

8. Tremellen KP, Kolo M, Gilmore A, Lekamge DN: Antimullerian hormone as a marker of ovarian reserve. Aust N Z J Obstet Gynaecol 2005, 45:20-24.

9. La Marca A, Giulini S, Tirelli A, Bertucci E, Marsella T, Xella S, Volpe A: AntiMüllerian hormone measurement on any day of the menstrual cycle strongly predicts ovarian response in assisted reproductive technology. Hum Reprod 2007, 22:766-771.

10. Jayaprakasan K, Campbell B, Hopkisson J, Johnson I, Raine-Fenning N: A prospective, comparative analysis of anti-Müllerian hormone, inhibin-B, and three-dimensional ultrasound determinants of ovarian reserve in the prediction of poor response to controlled ovarian stimulation. Fertil Steril 2010, 93:855-864.

11. Lee TH, Liu CH, Huang CC, Wu YL, Shih YT, Ho HN, Yang YS, Lee MS: Serum anti-Müllerian hormone and estradiol levels as predictors of ovarian hyperstimulation syndrome in assisted reproduction technology cycles. Hum Reprod 2008, 23:160-167.

12. Nardo LG, Gelbaya TA, Wilkinson H, Roberts SA, Yates A, Pemberton P, Laing I: Circulating basal anti-Müllerian hormone levels as predictor of ovarian response in women undergoing ovarian stimulation for in vitro fertilization. Fertil Steril 2009, 92:1586-1593.

13. Pigny $P$, Jonard $S$, Robert $Y$, Dewailly $D$ : Serum anti-Müllerian hormone as a surrogate for antral follicle count for definition of the polycystic ovary syndrome. J Clin Endocrinol Metab 2006, 91:941-945.

14. Broer SL, Mol B, Dólleman M, Fauser BC, Broekmans FJ: The role of antiMüllerian hormone assessment in assisted reproductive technology outcome. Curr Opin Obstet Gynecol 2010, 22:193-201.

15. Seifer $D B$, Baker VL, Leader B: Age-specific serum anti-Müllerian hormone values for 17,120 women presenting to fertility centers within the United States. Fertil Steril 2011, 95:747-750.

16. Shebl O, Ebner T, Sir A, Schreier-Lechner E, Mayer RB, Tews G, Sommergruber M: Age-related distribution of basal serum AMH level in women of reproductive age and a presumably healthy cohort. Fertil Steril 2011, 95:832-834.

17. La Marca A, Sighinolfi G, Giulini S, Traglia M, Argento C, Sala C, Masciullo C, Volpe A, Toniolo D: Normal serum concentrations of anti-Müllerian hormone in women with regular menstrual cycles. Reprod Biomed Online 2010, 21:463-469.

18. Ebner T, Sommergruber M, Moser M, Shebl O, Schreier-Lechner E, Tews G: Basal level of anti-Müllerian hormone is associated with oocyte quality in stimulated cycles. Hum Reprod 2006, 21:2022-2026.

19. Penarrubia J, Fabregues F, Manau D, Creus M, Casals G, Casamitjana R, Carmona F, Vanrell JA, Balasch J: Basal and stimulation day 5 antiMüllerian hormone serum concentrations as predictors of ovarian response and pregnancy in assisted reproductive technology cycles stimulated with gonadotropin- releasing hormone agonist-gonadotropin treatment. Hum Reprod 2005, 20:915-922.

20. Kwee J, Schats R, McDonnell J, Themmen A, de Jong F, Lambalk C: Evaluation of $\mathrm{AMH}$ as test for the prediction of ovarian reserve. Fertil Steril 2008, 90:737-743.

21. Smeenk JM, Sweep FC, Zielhuis GA, Kremer JA, Thomas CM, Braat DD: Antimüllerian hormone predicts ovarian responsiveness, but not embryo quality or pregnancy, after in vitro fertilization or intracyoplasmic sperm injection. Fertil Steril 2007, 87:223-226. 
22. Gnoth C, Schuring AN, Friol K, Tigges J, Mallmann P, Godehardt E: Relevance of anti-Müllerian hormone measurement in a routine IVF program. Hum Reprod 2008, 23:1359-1365.

23. Elgindy EA, El-Haieg DO, El-Sebaey A: Anti-Müllerian hormone: correlation of early follicular, ovulatory and midluteal levels with ovarian response and cycle outcome in intracytoplasmic sperm injection patients. Fertil Steril 2008, 89:1670-1676.

24. Barad DH, Weghofer A, Gleicher N: Comparing anti-Müllerian hormone (AMH) and follicle-stimulating hormone (FSH) as predictors of ovarian function. Fertil Steril 2009, 91:1553-1555.

25. Eldar-Geva T, Ben Chetrit A, Spitz IM, Rabinowitz R, Markowitz E, Mimoni T, Gal M, Zylber-Haran E, Margalioth EJ: Dynamic assays of inhibin B, antiMüllerian hormone and estradiol following FSH stimulation and ovarian ultrasonography as predictors of IVF outcome. Hum Reprod 2005, 20:3178-3183.

26. Hazout A, Bouchard P, Seifer DB, Aussage P, Junca AM, Cohen-Bacrie P: Serum antimüllerian hormone/müllerian-inhibiting substance appears to be a more discriminatory marker of assisted reproductive technology outcome than follicle-stimulating hormone, inhibin B, or estradiol. Fertil Steril 2004, 82:1323-1329.

27. Silberstein T, MacLaughlin DT, Shai I, Trimarchi JR, Lambert-Messerlian G, Seifer DB, Keefe DL, Blazar AS: Müllerian inhibiting substance levels at the time of HCG administration in IVF cycles predict both ovarian reserve and embryo morphology. Hum Reprod 2006, 21:159-163.

28. Lekamge DN, Barry M, Kolo M, Lane M, Gilchrist RB, Tremellen KP: AntiMüllerian hormone as a predictor of IVF outcome. Reprod Biomed Online 2007, 14:602-610.

29. Lie Fong S, Baart EB, Martini E, Schipper I, Visser JA, Themmen AP, de Jong FH, Fauser BJ, Laven JS: Anti-Müllerian hormone: a marker for oocyte quantity, oocyte quality and embryo quality? Reprod Biomed Online 2008, 16:664-670.

30. La Marca A, Sighinolfi G, Radi D, Argento C, Baraldi E, Artenisio AC, Stabile G, Volpe A: Anti-Müllerian hormone (AMH) as a predictive marker in assisted reproductive technology (ART). Hum Reprod Update 2010, 16:113-130.

31. Wang JG, Douglas NC, Nakhuda GS, Choi JM, Park SJ, Thornton MH, Guarnaccia MM, Sauer MV: The association between anti-Müllerian hormone and IVF pregnancy outcomes is influenced by age. Reprod Biomed Online 2010, 21:757-761.

doi:10.1186/1477-7827-9-115

Cite this article as: Lee et al.: The predictability of serum anti-Müllerian level in IVF/ICSI outcomes for patients of advanced reproductive age.

Reproductive Biology and Endocrinology 2011 9:115.

\section{Submit your next manuscript to BioMed Central and take full advantage of:}

- Convenient online submission

- Thorough peer review

- No space constraints or color figure charges

- Immediate publication on acceptance

- Inclusion in PubMed, CAS, Scopus and Google Scholar

- Research which is freely available for redistribution

Submit your manuscript at www.biomedcentral.com/submit 